\title{
Teaching for Learning: Towards Pedagogical Paradigm Shift in the Implementation of Polytechnic Curriculum in Nigeria
}

\author{
Olajide, Joseph Lekan (Ph.D), \\ Chief Lecturer \& Dean, Faculty of Business and Management Studies, Osun State \\ College of Technology, Esa-Oke, Nigeria
}

\begin{abstract}
The objective of teaching is learning. Teaching cannot be said to be successful without effective learning. The academic achievement got from the higher institutions these days depicts that teaching is going on without much learning. That is why students that graduate with distinction or first class from our institutions of higher learning are few and far between. A student that recently graduated with 5.00 GPA became instant news. But this should be the rule rather than the exception. More students should graduate with distinction and upper credit grades than lower credit and pass. Something should be done to tilt students' marks distribution towards the positive skew. and this is the objective of the Integrated Lecture Approach (ILA) being proposed in this paper. It advocates for the practice of teaching for learning (TFL) as opposed to the popular practice of teaching and learning (TAL) that goes on in our institutions. In TAL, teaching is considered as the responsibility of the lecturer while learning is the sole responsibility of the students but TFL makes it the responsibility of the teacher not just to teach effectively but to also ensure that the students learn effectively. This is what the ILA is about. This paper seeks to make a case for the integration of the following responsibilities into the lecturers' schedule: variation of teaching methods, motivation of students, inculcation of success mindset and time management practices, providing guardianship to students, and close monitoring of students' study reading practices. Even after classroom interactions with students, lecturers should exert some form of control influence on the students in the specified areas.
\end{abstract}

Key words: Teaching and learning; Teaching for Learning; Integrated Lecture Approach;, Academic success mindset; time management. 


\section{Introduction}

The time has come to begin to take a second look into the bell curve as a normal distribution for tertiary students' academic achievement. A number of factors account for the bell curve distribution of students' achievement scores in the tertiary institutions - a situation in which $84 \%$ of the students are shut out of the A' grade. The first is the use of lecture method of instruction in higher institutions which is not without its weaknesses. Kelly (2017) observes that students who are weak in note-taking skills may have trouble understanding what they should remember from lectures. Students who are not auditory learners or have other learning styles may not be as engaged by lectures and may have a harder time absorbing the material. These students may find lectures boring, causing them to lose interest. Unless they are particularly bold, students may not feel that they are able to ask questions as they arise during lectures. And, lecturers may not get a real feel for how much students understand because there is little opportunity for exchanges during lectures. Usually, very little exchange occurs between the lecturer and students, other than a few scattered questions from listeners. This ought to be changed to another method that promotes close and frequent interaction of students and lecturers.

The second factor is the lack of effective monitoring. Shuell (1986) observes that until recently, research into learning and teaching in higher institutions has focused on what the lecturer does rather than on what the learner does. However, recent research into student learning indicates that what your students do in order to learn is of the greater importance. $\mathrm{He}$ is of the opinion that student-centred teaching is built on the assumption that what the student does is actually more important in determining what is learned than what the teacher does so he emphasizes student-centred and active learning approaches to engage students in their learning.

Effective monitoring is needed for students in tertiary institutions because it is a free environment full of distractions. In his submission on reasons why most students do not upgrade to straight 'A', Ajayi (2013) points out that the school is fun-filled with extracurricular clubs and leisure activities. He further observes that students are in the habit of wasting their time instead of being productive ... and they end up with C's and B's instead of the A's they deserve and should honestly desire. This much is confirmed by Olajide and Olatipe (2016) when they lament that it is a fact that the higher institutions are full of distractions where students are surrounded by distractive co-curricular and extracurricular activities. Students often get themselves involved in these activities so that they will not just 'pass through the institution', but also for 'the institution to pass through them'. It is not uncommon, therefore, to see many students engage in games and sporting activities, socio-cultural activities, religious activities, and business enterprises to name 


\section{The World Conference on Research in}

just a few, to the detriment of their academic pursuits. Students in tertiary institutions, therefore, need constant and effective guardianship support to remain focused on their primary assignment in the citadel of learning: to attend lectures not only regularly but also

punctually, to engage in productive study reading, to constructively engage in effective time management practices; and operate on a clear success mindset.

The assumption that students in tertiary institutions are matured may not be totally correct. The trend these days is that a high percentage of students admitted to study in tertiary institutions are teenage adolescents and young adults who, according to Elmore (2012), seem to require more time to actually "grow up" and prepare for the responsibility that comes with adulthood. He insists that they are missing many of the marks of maturity they should possess. This might be why QuinStreet Inc (2017) observes that there's a lot more to teaching than just showing up and giving the day's lesson. Being an effective teacher is so much more than stand in front of a class lecturing. The best teachers are happy to extend their role beyond lecturing because they know it makes the students' educational experience so much more beneficial.

Every student has got the potential to get the best grades in their subjects and to come tops of the class if they faithfully practise study reading. Reading varies in type and purpose. While reading can be done for the purpose of obtaining pleasure, some read to kill the time, and some read to lure themselves to sleep. The most important purpose of reading for a student is to learn. Learning is largely connected to comprehension. Reading, therefore, is at the heart of comprehension. Complete understanding of a text is achieved through study reading. Study reading requires the student to pay close attention to the text. Much like intensive reading, study reading is done with undistracted attention to details and analysis especially when one is aware that the material will later have to be recalled, discussed, evaluated and applied. Olajide and Faniran (2012) argue that a student who has obtained an overall understanding of the text is expected to not only be able recall it in the original order, but also be able to apply, analyze, synthesize, and evaluate the information.

\section{Effective Learning}

Learning is defined as a change in knowledge: a relatively permanent change in, or acquisition of, knowledge, understanding, or behavior (Microsoft,, 2009). Gross (2017) describes it as the act of acquiring new, or modifying and reinforcing existing, knowledge ,behaviors, skills, values, or preferences which may lead to a potential change in synthesizing information, depth of the knowledge, attitude or behavior relative to the type and range of experience. Karban (2015) says the ability to learn is possessed by humans, animals, plants and some machines. Progress over time tends to follow a learning curve. Learning does not happen all at once, but it builds upon and is shaped by previous 


\section{The World Conference on Research in}

knowledge. To that end, learning may be viewed as a process, rather than a collection of factual and procedural knowledge. Learning produces changes in the organism and the changes produced are relatively permanent.

Eberly (2015) goes further to provide the following seven principles of effective learning which are distilled from research from a variety of disciplines.

i. Students' prior knowledge can help or hinder learning.

ii. How students organize knowledge influences how they learn and apply what they know.

iii. Students' motivation determines, directs, and sustains what they do to learn.

iv. To develop mastery, students must acquire component skills, practice integrating them, and know when to apply what they have learned.

v. Goal-directed practice coupled with targeted feedback enhances the quality of students' learning.

vi. Students' current level of development interacts with the social, emotional, and intellectual climate of the course to impact learning.

vii. To become self-directed learners, students must learn to monitor and adjust their approaches to learning.

While this paper will not trust students for so much of self direction, it advocates purposeful motivation and monitoring that will imbue in the students goal-directed practices that will receive targeted feedback which will ultimately enhance the quality of students' learning.

\section{Student Maturity and Learning}

The status of maturity according to Wikipedia is distinguished by the shift away from reliance on_guardianship_and the oversight of an adult in decision-making acts. But experts have observed that many students today appear mature but are actually missing the key components of maturity. Elmore (2012) insists that students today are consuming information that they are not completely ready to handle. The adult part of their brain is still forming and is not ready to apply all that the society throws at it. Their mind takes it in and files it, but their will and emotions are not prepared to act on it in a healthy way. They can become paralyzed by all the content they consume. One of the seven indices of maturity he gives is that a mature person is able to keep long-term commitments: but are majority of the students able to do this? The plain truth is that the students are most often distracted and they lose focus easily. Sheldon and Kasser (2001) are of the opinion that while older persons are generally perceived as more matured and to possess greater credibility, psychological maturity is not determined by one's_age. This accounts for why many otherwise level-headed and promising new entrants to a tertiary institution end up derailed and disoriented by the companies they keep. While many of them get their destiny permanent short-circuited, many that recover remain at the very low rung of their academic achievement. The presenter travelled that road and missed second class upper 
grade GPA by .01. In the same vein, Erikson (1968) posits that although psychological maturity is specifically grounded in the autonomy of one's decision-making ability, these outcomes are deeply embedded in not only cognition, but also in lifelong processes of emotional, social and moral development. The implication is that even when the student is favoured by age and cognitive competence as measures of maturity, his efforts in the citadel of learning may be ruined by inherent emotional, social, or moral dereliction hence the need for proper monitoring by the lecturer who serves as a guardian or parent figure.

\section{Monitoring and Learning}

Progress monitoring focuses on individualized decision-making in general and special education with respect to academic skill development. Progress monitoring, according to Fuchs and Fuchs (1992), is conducted to estimate rates of improvement, identify students who are not demonstrating adequate progress and therefore require additional or alternative forms of instruction, and/or compare the efficacy of different forms of instruction and thereby design more effective, individualized instructional programs for problem. In their paper on 'monitoring student reading progress, they identify 4 methods: Question answering tests, Recall procedures, Cloze Techniques, and Maze procedures. It should be noted however that in ILA monitoring is not limited to students' progress in tests but progress before and after tests are administered. To ensure that students do actually practice study reading, the lecturer is expected to prompt the study reading exercise, keep track of the exercise by mandating students to provide jottings of their readings, attempt questions from home daily and submit same without fail at specified times. Institutions also should facilitate the practice of study reading and challenge the students to seriously engage in it.

\section{External and Internal Factors in Learning}

Factors affecting learning are external and internal. Aggarwal (2009) discusses external factors to include heredity, status of students, and learning environment. While heredity indices like native intelligence may not be controlled, this presenter is of the opinion that students in tertiary institutions have undergone standardization having passed through the rigours of admission and matriculation examinations. It is now the responsibility of the educational institutions to ensure that other factors like bad ventilation, unhygienic living and poor or non illumination are controlled. Also, the students must be monitored to make the best of the learning environment like the classroom, library, internet facilities, and reading room.

The following thirteen internal factors that affect students' learning are identified by Mangal (2002): 
1.Goals or purposes: Assist students to have a success mindset having not only immediate goal but also distant goals that are specific and clear.

2. Motivational behavior: Students should be motivated so that they stimulate themselves with interest.

3.Interest: The lecturer must raise interests among students for the best learning

4.Attention: Lecturers must do everything to secure and sustain the attention of the student.

5.Drill or practice: Giving students tasks to accomplish and correcting faults and errors

6.Fatigue: Vary teaching methods

7.Aptitude: Promote student's ability to acquire skills and knowledge through training and practice.

8.Attitude: The positive attitude of the student must be promoted for learning a subject or topic.

9.Emotional conditions: Provoking or embarrassing the student in front of a class is counterproductive and must be discouraged.

10. Speed, Accuracy and Retention: These three elements must be enhanced.

11. Learning activities: The lecturer must exert discipline and bring his personality to bear through warm interaction.

12. Testing: Tests must be given and feedback provided. Practice questions must be provided to students

13. Guidance: Students in tertiary institutions need constant guidance especially to avoid distractions and apply time management skills.

The ILA being put forward in this paper requires the lecturers to be actively involved in monitoring and assisting the students to control and maximize the benefits of these factors.

\section{Teaching for Learning (TFL)}

The sole purpose of teaching is learning. A teacher at any educational level ought not to be deemed as successful until a very high percentage of the students has learned effectively and performed very high on learning achievement scale. Much like in Learning for Mastery (LFM) students must be assisted to achieve a high level of mastery e.g. $90 \%$ on a knowledge test in prerequisite knowledge. If a student does not achieve mastery on the test, they are given additional support in learning. As in LFM Levine (1985) opines that in TFL there is a shift in responsibilities, so that student's failure is more due to the instruction and not necessarily lack of ability on his or her part. The challenge therefore, is providing enough time and employing suitable instructional strategies so that all students can achieve the desired very high level of learning

Proponents of Teaching for Learning like Eberly (2015) provide the following 7 indices of effective teaching. It involves: 
1. Acquiring relevant knowledge about students and using that knowledge to inform course design and classroom teaching:

2. Aligning the three major components of instruction: learning objectives, assessments, and instructional activities.

3. Articulating explicit expectations regarding learning objectives and policies

4. Prioritizing the knowledge and skills we choose to focus on.

5. Recognizing and overcoming our expert blind spots.

6. Adopting appropriate teaching roles to support our learning goals

7. Progressively refining our courses based on reflection and feedback.

They recognize teaching as a complex, multifaceted activity, often requiring lecturers to juggle multiple tasks and goals simultaneously and flexibly. The set of principles can make teaching both more effective and more efficient by helping in creating the conditions that support student learning and minimize the need for revising materials, content, and policies. Implementing the principles requires a commitment in time and effort, but it often saves time and energy later on. They go on to recommend the following kinds of activities that can be used to facilitate student-centred learning and teaching and actively engage with the content and to provide variety within the lecture or tutorial:

$\begin{array}{ll}\text { Active learning spaces } & \text { Debates } \\ \text { Blended and online learning } & \text { Discussion } \\ \text { Brainstorming } & \text { Flipped Classroom } \\ \text { Case studies } & \text { Group work } \\ \text { Questioning } & \text { Simulations } \\ \text { Teaching diverse groups } & \end{array}$

In addition to the above this paper advocates the involvement of lecturers in refocusing the students' success mindset, moderate their time management practices, remotely monitoring their study reading practices, and providing needed guardianship.

\section{Review of Integrated Lecture Approach (ILA) in TFL}

\section{Justification for ILA}

The adoption of ILA is expected serve some useful purposes for the students and the institution:

- To promote the rate of students' success

- To stem the rate of students' failure

- To stem the rate of examination mal-practices

- To stem the rate of suspension and expulsion of students for examination mal-practices and miscellaneous other infractions 
- To ensure that more students graduate in higher grades

- To stem the tide of anti-social behaviours among students

- To maximize the use of the library facilities

- To get lecturers to be more interested in students' affairs even outside of the classroom

- To get lecturers to diversify and enrich their teaching method

\section{Objectives of ILA}

If properly adopted and practiced, ILA is designed to meet the following objectives, among others

- To promote in the lecturers higher sense of responsibility and commitment

- To raise the standard of education by making teaching and learning more effective

- To shift to the lecturers the responsibility of students' learning

- To institutionalize the practice of study reading

- To assist the students to achieve their academic goals

- To promote qualitative and positive studentship

- To promote scholarship among students

- To inculcate effective time management in students

- To imbue in the students positive academic success mindset

- To promote in the students a high sense of responsibility and commitment

\section{Operational Procedure of ILA}

To be effective in practice, practitioners of ILA are expected to engage in the following activities, among others

a) Students should be regularly encouraged to cultivate positive academic success mindset and aim for " $A$ ' grades in each course.

b) Students should be closely monitored in their study reading and time management efforts

c) Institutional arrangement should be made for mandatory tutorial sessions daily on the time-table to ensure that the students go over the day's topic before they return home after the day's work

d) Since the course lecture holds only once a week, the lecturer should give students assignments to submit either physically to the pigeon-hole or electronically to dedicated Whatsapp/Telegram platforms everyday of the week including weekends

e) To ensure that the students visit the library daily during the day, the course lecturer should provide students with suggested topics from books and online sources which they must show proof of reading by submitting their jottings.

f) To ensure that students read and do their take home assignments after school has closed, the institution should make provisions for uninterrupted electricity supply in the classes to serve as reading rooms from 6.00 to 8.00 every night and 5.00 to 7.00 every morning.

g) Students should also be provided regular and uninterrupted internet access. 
h) Institutions should make provision for adequate and functional security and medical to ensure students' safety and well-being.

\section{ILA and Study Reading}

The teaching of study reading is embedded in the polytechnic General Studies curriculum prepared by the National Board for Technical Education (NBTE). One of the general objectives of Use of English taught in the first semester of the first year of National Diploma programme is 'development of appropriate study skills' which invariably include note-taking, use of dictionary, library, scanning, skimming, normal, and study reading (NBTE,1999). The students are expected to use the different methods of reading as they undertake their studies but more often than not, as confirmed by Olajide, Olatipe, Adedeji and Fadare (2018), this expectation is defeated as most students put up a laissez-faire attitude to reading delaying serious reading till the examinations are imminent. A visit to the library shows that while the library is jam-packed during examinations, students are usually very scanty in the library long before examinations. The way round this laxity is to regulate and monitor the students' practice of study reading. Everything necessary should be put in place to ensure that they jettison their laissez-faire attitude and give their studies a top priority in their daily schedule. This is made possible through ILA.

\section{ILA and Time Management}

Also of vital importance to the successful studentship is time management. Students in the higher institutions enjoy a good measure of personal freedom and unrestrained latitude to waste their time. The nature of the campuses also does not help matters. Very many activities are going on which could prove distractive or eat into student's study time. Ajayi (2013) notes that with so much to do, it can be easy for students to become overwhelmed, stressed up, and eventually burn out. He opines that 'students can help themselves stay sane and still get everything done by developing a good time management skills. Time management is about effectiveness and efficiency. Efficiency is about getting more done while effectiveness is about getting the right stuff done. Students should be trained and assisted to spend their time doing things right and doing right things. Wong (2017) identifies four quadrants of tasks in the time management matrix as follows:

- Quadrant 1: Important and urgent (e.g. last-minute assignments and projects)

- Quadrant 2: Important but not urgent (e.g. spending time with your family or exercising)

- Quadrant 3: Not important but urgent (e.g. some phone calls and text messages)

- Quadrant 4: Not important and not urgent (e.g. watching YouTube videos) He advises an aspiring effective student to spend at least $80 \%$ of the time on Quadrant 2 tasks. This is in the spirit of the maxim that says, 'all work and no play make Jack a dull boy'. A good student should not wait until studying becomes urgent before he starts to read. A student who manages his time well ought to be more relaxed during examination. 


\section{The World Conference on Research in}

Adoption of ILA in tertiary institutions will provide a check against these laxities on the part of the students and for lecturers to integrate the monitoring and guardianship responsibilities with the lecturers' schedule.

\section{ILA and the Lecturer}

As observed earlier, implementing the principles espoused in ILA requires a commitment in time and effort, but it often saves time and energy later on. In operating learning-driven teaching so much depends on the efforts of the lecturer. Beers (2006) observes that the processes of acquiring new information and internalizing that information cannot occur at the same time, so practice sessions should follow short periods of input. The students must therefore be provided with series of practice exercises which they must diligently work at. Students are enriched when they receive periodic feedback about their progress with challenging activities. Students who plod along through class with no idea how they are doing are not likely to adjust along the way when headed in the wrong direction.

Beers' (2006) work dwells on the twin factors of students' motivation and emotion. On motivation he observes that the amount of attention that students give to a situation depends heavily on their motivation at the time of the event. Lecturers can greatly affect motivation by removing threats, reducing stress, providing positive feedback, and introducing novelty. Students are often off task because they don't see the urgency in completing what was assigned to them. When an activity runs short and time is left at the end of the class period, few students will start their homework as directed or study for the test to be held at the end of the week. The end of the period is a great time for practice or reflection, but this must be planned for ahead of time. Unless a student is motivated and monitored opportunities like these will be wasted on frivolous activities and chit-chats. The responsibility to motivate the students on time management and success mindset falls on the lecturer

Lecturers can also either make emotion work for the students or allow emotion to get in the way of their learning. To make emotions work positively, lecturers need to have strategies for determining how students feel from time to time. Finding out about students' life outside the classroom can give teachers valuable information about why students act the way they do. Discussing students' feelings with them also shows that teachers care about them as individuals. As the saying goes, "they don't care how much you know until they know how much you care." Lecturers should also share their own emotions with students when appropriate, and they should model a love for learning and accomplishment.

For students to succeed in their studies, Olajide, Adeosun, and Adeyeri (2017) observe that they must incorporate into their daily activities a significant dose of their academic 
pursuits and reading plans. However, the fact of life is that not all students can be equally serious-minded or self-motivated. Some are bound to be unserious, slack and unwilling, needing a pushing influence before they can invest optimum time and efforts in their study. This set of students does exist and they can constitute a menace to the institution. To mitigate the incipient vagaries of life and the prevailing side attractions provisions should be made to prod the indolent and not-so-self-motivated students so that their dreams will not be scuttled. The lecturer should be there to provide the driving force that will inspire, enthuse, and spur the students to engage in regular study reading.

\section{Conclusion and Recommendation}

Successful practice of ILA advocated in this paper is dependent to a very large extent on the readiness and attitude of the lecturers. Attitude is a hypothetical construct that represents an individual's like or dislike. The Oxford Advanced Learners' Dictionary describes it as 'the way we think and feel about somebody or something'. Also as 'the way we behave towards somebody or something that shows how we think or feel'. Jung (1971) defines it as 'a readiness of the psyche to act or react in a certain way'. Psychologists believe that attitudes are composed from various forms of judgments and developed on the Affective, Behavioural Change and Cognition (ABC) model. The affective component is the psychological response that expresses an individual's preference for an entity. The behavioural intention is a verbal indication of the intention of an individual, while the cognitive response is a cognitive evaluation of the entity to form an attitude. Most attitudes in individuals have been explained to be a result of their observational learning from the environment. According to Wikipedia, attitudes are positive, negative or neutral views of an object which may be a person, behaviour or an event. People can also be said to be ambivalent towards a target, if they simultaneously possess a positive and a negative bias towards the object in question.

\section{References}

[1] Aggarwal, J.C (2009) Essentials of Educational Psychology (2nd ed.). Vikas Publishing House Pvt Ltd. p. 596. ISBN 9788125922926.

[2] Ajayi, Y.O. (2013): Getting Distinction Grades in your Exams Every-time. Abuja, Applewells Publishing Company

[3] Bhatia, H.R (1973). Elements of Educational Psychology. Orient Blackswan. p. 558. ISBN 9788125000297.

[4] Beers, B. (2006) Learning-Driven Schools Copyright (C) 2006 by Association for Supervision and Curriculum Development

[4] Eberly Center for Teaching Excellence \& Educational Innovation (2008, 2015): A Teaching for Learning: Theory and Research-based Principles of Learning: Carnegie Mellon University. https://www.cmu.edu/teaching/principles/learning.html [6] Elmore, T. (2012): The Marks of Maturity https://www.psychologytoday.com/blog/artificial-maturity/201211/the-marks-maturity 
[7] Erikson, E. H. (1968). Identity: Youth and Crisis. W. W. Norton. ISBN 978-0393-31144-0. Retrieved 9 June 2013.

[8] Fuchs, L.S. \& Fuchs, D. (1992) Identifying a Measure for Monitoring Student Reading Progress. School Psychology Review 21, 1, 45-46)

[9] Gross, R. Psychology (2017): The Science of Mind and Behaviour 6E, Hachette UK, ISBN 9781444164367 retrieved June 2017

[10] Jung, C.G. (1971) Psychology types: collected works. 6. Princeton, N. J. Princeton University Press

[11] Karban, R. (2015). Plant Learning and Memory. In:Plant Sensing and Communication. Chicago and London: The University of Chicago Press, pp. 31-44, [1].

[12] Kelly, M. (2017): Lecture Pros and Cons. https://www.thoughtco.com/commoncore-state-standards-3194603

[13] Levine, D. U. (1985). Improving student achievement through mastery learning programs Jossey-Bass. ISBN 9780875896458

[14] Mangal, S.K. (2002): Advanced Educational Psychology (2nd ed.). PHI Learning Pvt. Ltd. p.536

[15] Microsoft Corporation (2009): Microsoft Encarta (c) 1993-2009

[16] National Board for Technical Education NBTE (1999): General Studies Course Specifications for National Diploma and Higher National Diploma Programmes. Kaduna.

[17] Olajide, J.L \& Olatipe, S.O (2017): Self-Communication in Study Reading Among Polytechnic Students In Nigeria. Issues in Curriculum and Language Education. Book of Readings in Honour of Prof. Araromi, Institute of Education, University of Ibadan

[18] Olajide, J.L; Adeosun, T.H \& Adeyeri, L.O (2018): Effect of Integrated Study Reading on Polytechnic Students' Success Mindset and Academic Achievement Research on Humanities and Social Sciences 8:12

[19] Olajide, J.L \& Faniran, O.A. (2012): Effective Communication in English $3^{\text {rd }}$ Edition; Ilesa, Glorious Prints

[20] QuinStreet Inc (2017): Teacher Certification http://www.teachercertification.org/a/the-many-roles-of-the-teacher.html

[21] Sheldon, K. M. \& Kasser, T. (2001): Getting Older, Getting Better? Personal Strivings and Psychological Maturity Across the Life Span. Developmental Psychology. 37 (4): 491-301. doi:10.1037/0012-1649.37.4.491. PMID 11444485.)

[22] Shuell, T.J. (1986): Cognitive Conceptions of Learning, 429 ).

[23] Smith, K. L. (2016): Teaching and Learning University of Central Florida Faculty Centre for Teaching and Learning

[24] Wikipedia (2008) Attitude (Psychology) http://en.wikipedia.org/wiki/Attitude (psychology) Retrieved 12/3/2008. 
[25] Wikipedia, the free encyclopedia Maturity (psychological)

[26] Wong, D (2017): Five Easy Ways to Improve your Examination Performance https://personalexcellence.co/blog/exam/ Assessed 05/01/2017 